\title{
Indústria, Serviços e Crescimento Econômico dos Municípios Brasileiros
}

\author{
Carlos C. S. Saiani \\ IERI/UFU \\ ssaiani@ufu.br
}

\author{
Michele Polline Veríssimo \\ IERI/UFU e CNPq \\ $\underline{\text { micheleverissimo@ufu.br }}$
}

\begin{abstract}
Resumo: A literatura baseada em Kaldor defende a indústria como o motor do crescimento econômico (engine of growth hypothesis). Contudo, trabalhos recentes destacam a relevância dos serviços para impulsionar o crescimento. Contribuindo para tal debate, o objetivo deste estudo é avaliar os efeitos das participações dos setores industrial e de serviços sobre o crescimento do produto per capita dos municípios brasileiros. Além disso, é averiguado se há efeitos heterogêneos em função do nível de renda municipal per capita e da importância de cada setor para a economia dos municípios. Para isso, são realizadas estimações econométricas em painel com dados de 1999 a 2012. As evidências sinalizam que a participação industrial tem papel importante sobre o crescimento nos municípios com menores níveis de renda. Porém, em municípios com níveis superiores de renda, a importância dos serviços como motor do crescimento é relativamente maior. As evidências sugerem, ainda, que as relações entre o crescimento econômico e as participações dos dois setores têm um formato próximo a um "U-invertido".
\end{abstract}

Palavras-chave: Crescimento Econômico; Indústria; Serviços; Municípios; Dados em Painel.

\begin{abstract}
The literature based on Kaldor defends industry as the engine of economic growth. However, recent studies highlight the relevance of services to increase growth. Contributing to such discussion, the objective of this paper is to evaluate the effects of industry and service shares on the Brazilian municipalities GPD per capita growth. Also, we investigate whether there are heterogeneous effects due to the municipal GDP per capita level and the relative importance of those sectors for the municipalities economies. For that, we estimate econometric panel data models from 1999 to 2012. The evidences indicate that industry share plays an important role in municipalities growth with lower income levels. However, for municipalities with higher income levels, there is a major importance for services as an engine of growth. The evidences also suggest that the relationships between growth and the two sectors shares in GDP have a shape close to an "inverted U".
\end{abstract}

Keywords: Economic Growth; Industry; Services; Municipalities; Panel Data.

\section{Área 1 - Indústria e competitividade}

1.3 Crescimento, produtividade e competitividade

Classificação JEL: O40; O41; R11. 


\section{Introdução}

A literatura fundamentada pelos pressupostos de Kaldor aponta a indústria como motor do crescimento econômico (engine of growth hypothesis). Nessa visão, atividades industriais são consideradas como detentoras de um conjunto de características que estimulam o crescimento, tais como: i) economias de escala que influenciam a produtividade do próprio setor e da economia como um todo; ii) maiores elasticidades-renda da demanda em comparação aos setores de bens primários; iii) maior capacidade de inovação e de promoção de efeitos de aprendizagem; iv) efeitos de encadeamento (spillovers) para frente e para trás na cadeia produtiva. Assim, a industrialização é defendida como uma condição necessária para o crescimento no longo prazo, promovendo o progresso tecnológico e a convergência de renda (catching-up). Vários trabalhos apresentam evidências que corroboram a hipótese da indústria como um motor do crescimento.

Contudo, principalmente para períodos mais recentes e economias mais desenvolvidas, evidências também sinalizam a importância dos serviços para o crescimento econômico. No geral, a explicação é fundamentada pelo argumento de que a queda da participação industrial no produto e no emprego pode ser um processo "natural" associado ao aumento da renda per capita ao longo do tempo. O aumento da renda eleva mais a demanda por serviços comparativamente a bens industriais. Já aumentos da produtividade industrial liberam mão de obra, que é absorvida pelo setor de serviços. Ao longo do tempo, há mudança estrutural nos serviços, que deixam de ser unicamente intensivos em mão de obra e passam a ser dotados de maior conhecimento e intensidade tecnológica. Ou seja, tal setor também apresenta ganhos de produtividade, cujos efeitos se disseminam para outros setores, inclusive a indústria. Assim, vários autores apontam a possibilidade de os serviços passarem a dirigir o crescimento do produto em detrimento da indústria; ou seja, de se tornarem o motor do crescimento.

O presente estudo pretende contribuir para tal debate, apresentando evidências inéditas para os municípios brasileiros. Por meio de estimações econométricas em painel com dados referentes aos anos de 1999 a 2012, o objetivo é avaliar qual setor (indústria ou serviços) é o motor do crescimento, ou seja, impacta mais sobre a taxa de crescimento real do Produto Interno Bruto (PIB) per capita municipal. Em consonância com a literatura empírica, são mensurados os efeitos das participações dos valores adicionados da indústria e dos serviços no PIB para todos os municípios com dados disponíveis. Além disso, também foram estimados os modelos para os municípios divididos em três grupos segundo os quintis da distribuição dos PIBs municipais per capita médios no período, com o intuito de avaliar se os efeitos das participações setoriais diferem entre os municípios com níveis distintos de PIB (efeitos heterogêneos), como é constatado em trabalhos para países. No geral, estes observam maiores efeitos da indústria em países em desenvolvimento e maiores efeitos dos serviços em países desenvolvidos. Assim, o motor do crescimento se alteraria conforme o nível de renda.

Outra hipótese avaliada é a de que, dada a possível interdependência entre a indústria e os serviços, o crescimento econômico seria estimulado pela maior diversificação entre os setores econômicos e não pela especialização em um deles. Como em qualquer discussão sobre diversificação versus especialização, deve-se considerar, ainda, que a diversificação torna a economia menos dependente apenas de um conjunto de atividades, de modo que o efeito de crises em um pode ser "suavizado" pelos demais. Em contrapartida, a especialização pode resultar em ganhos de produtividade benéficos ao crescimento. Para medir o grau de especialização/diversificação é adaptado um indicador de Gini-Hirschmann para as participações da indústria e dos serviços.

A terceira linha de análise do presente estudo é a avaliação da hipótese dos efeitos médios das participações da indústria e dos serviços sobre o crescimento econômico não serem lineares. Ou seja, os sinais dos coeficientes estimados associados às participações setoriais mudarem a partir de dada participação. Assim, os efeitos seriam diferentes segundo a importância do setor. Para testar essa hipótese, são aqui propostos e estimados modelos nos quais as participações da indústria e dos serviços são consideradas em uma função quadrática (polinômio de $2^{\circ}$ grau).

$\mathrm{O}$ estudo divide-se em três seções, além desta introdução e das considerações finais. $\mathrm{Na}$ segunda seção, é feita uma revisão da literatura que fundamenta teórica e empiricamente as hipóteses 
testadas. Na terceira seção, são discutidas as estratégias empíricas (metodologia) e são apresentadas algumas análises descritivas. Finalmente, na quinta seção, os resultados obtidos são avaliados.

Resumidamente, as evidências encontradas sinalizam que a participação industrial tem papel importante sobre o crescimento econômico nos municípios com menores níveis de PIB per capita médio. Porém, nos municípios com maiores níveis de PIB per capita, a importância dos serviços como motor do crescimento é relativamente superior, o que condiz com resultados da literatura para países. Além disso, as evidências sugerem que as relações entre o crescimento econômico municipal e as participações da indústria e dos serviços apresentam um formato próximo a um "U-invertido". Ou seja, à medida que a participação de um dos setores aumenta, o crescimento econômico é maior; contudo, este passa a diminuir a partir de dada participação.

\section{Fundamentação teórica e empírica}

\subsection{Indústria versus serviços: motor do crescimento econômico ${ }^{1}$}

Vários trabalhos destacam a relevância do setor industrial como o "motor" do crescimento econômico (engine of growth hypothesis), fundamentando-se, principalmente, em argumentos kaldorianos. Segundo Kaldor (1966), a indústria possui características capazes de estimular o crescimento econômico pelo lado da demanda, liderada pelas exportações, principalmente de produtos manufaturados. Esta visão, ao discutir a importância industrial, pressupõe que os setores da economia não são iguais, sendo o crescimento econômico mais dependente da expansão dos setores com atributos mais favoráveis à expansão do produto/renda (THIRLWALL, 2005).

Destarte, para Kaldor, a compreensão do crescimento exige análises setoriais. Atributos da indústria, como rendimentos crescentes, diferem aos de outros setores, como agricultura e mineração (rendimentos decrescentes). Assim, crescimentos distintos entre economias seriam explicados pelas "Leis de Kaldor". Em síntese, estas pressupõem: i) relação positiva entre os crescimentos da indústria e do produto; ii) relação positiva entre o crescimento da indústria de transformação e o aumento da produtividade no setor, como resultado de rendimentos estáticos e dinâmicos de escala (Lei de Kaldor-Verdoorn); iii) relação positiva entre a produtividade da indústria de transformação e o aumento da produtividade na economia como um todo; e iv) restrição ao crescimento no longo prazo pelo lado da demanda, em especial por exportações (de manufaturados) e, consequentemente, do balanço de pagamentos (THIRLWALL, 2005, LAMONICA; FEIJÓ, 2011).

Pela análise das Leis de Kaldor, a indústria seria, então, um setor "especial” comparado aos demais e a industrialização (avanço da participação industrial no produto) seria fundamental ao crescimento econômico no longo prazo. Isto porque a indústria se caracteriza pela presença de economias estáticas e dinâmicas de escala, de forma que sua produtividade é uma função crescente de sua produção. Além disso, o setor é o principal locus de acumulação de capital e de mudanças tecnológicas, sendo que grande parcela do progresso tecnológico da agropecuária e dos serviços é difundida a partir da indústria, que produz os bens de capital empregados nos demais setores. Outra justificativa é de que os efeitos de encadeamento para frente e para trás na cadeia produtiva são mais fortes na indústria e resultam em externalidades positivas aos investimentos em conhecimento e tecnologia, com transbordamentos para a agropecuária e o setor de serviços.

Deve-se considerar, ainda, que a elasticidade-renda das importações de bens industriais é maior do que a das importações de primários (Lei de Engel), de modo que o aumento da renda tende a reduzir a participação da agropecuária no produto devido ao deslocamento da demanda de bens primários para produtos industrializados. Adicionalmente, a industrialização é tida como necessária para aliviar a restrição de balanço de pagamentos ao crescimento econômico no longo prazo, uma vez

\footnotetext{
${ }^{1}$ Embora o referencial teórico utilizado para balizar o estudo seja relacionado à literatura para países, trata-se de trabalhos consagrados pela literatura econômica, que podem ser utilizados para fundamentar uma análise para municípios. Análises empíricas específicas para municípios são pouco exploradas pela literatura, o que se configura como uma contribuição do presente estudo para o preenchimento de uma lacuna da literatura..
} 
que as exportações de produtos industriais podem resultar em divisas para compensar as importações (OREIRO; FEIJÓ, 2010, SZIRMAI; VERSPAGEN, 2011).

Thirlwall (2005) destaca que, para a indústria ser considerada como "especial", é preciso que o crescimento do produto não tenha estreita relação com o crescimento de outros setores, tais como a agricultura, mineração ou serviços. Segundo o autor, é mais difícil encontrar uma correlação significativa entre o crescimento do PIB e o crescimento do setor agrícola. A correlação entre o crescimento do PIB e o crescimento do setor de serviços é mais forte, contudo, o autor argumenta que, neste caso, a direção da causalidade pode ser inversa - crescimento do produto resultando em expansão dos serviços -, pois a demanda por muitos serviços é derivada da demanda por bens industriais.

Nessa linha de raciocínio, Baumol (1967) argumenta que o setor de serviços funciona a "reboque" do industrial e que as características dos serviços tornam sua dinâmica insuficiente para ser o "motor" do crescimento. Para o autor, a produtividade do trabalho industrial, devido às inovações de processo, cresce mais rapidamente do que a dos serviços. Ademais, defende que os serviços não sustentam isoladamente aumentos constantes e cumulativos da produtividade derivada da acumulação de capital, inovação de processo ou economias de escala, o que torna a produtividade deste setor relativamente inferior à produtividade da indústria no longo prazo.

Baumol (1967) ressalta, ainda, que a participação dos serviços no emprego total tende a ser maior em economias de rendas mais elevadas. Para o autor, isso ocorre em função dos níveis salariais mais elevados na atividade, embora estes não sejam acompanhados de ganhos de produtividade, visto que o setor de serviços, em geral, utiliza pouca tecnologia e emprega mão de obra pouco qualificada. Em síntese, por Baumol (1967) entender o setor como de baixa produtividade, que, na maior parte, é intensivo em trabalho e inelástico a inovações produtivas, a ampliação da sua participação na economia restringe o crescimento devido ao seu baixo desempenho produtivo, e eleva custos com mão de obra, gerando a chamada "doença de custos de Baumol".

Essa visão do papel secundário e residual dos serviços para o crescimento, disseminada pelo desenvolvimentismo tradicional (industrialista), é contestada pela literatura recente (pósindustrialista), dada a observação de que o setor se transforma ao longo do tempo em fornecedor de serviços modernos intensivos em informação e conhecimento, que, além de renda e emprego, gera externalidades importantes para os demais setores. Segundo Cardoso e Perobelli (2013), a visão pósindustrialista fundamenta-se nos serviços como centro das atividades econômicas e no domínio do capital humano como chave para a produção. Como os serviços são intensivos em capital humano e, assim, têm capacidade de permear todas as atividades econômicas, o setor é fundamental para o crescimento. Sendo assim, a possibilidade de fornecimento de insumos para outras atividades faz com que o setor atue para frente e para trás em várias cadeias produtivas, permitindo a articulação dos elos de distintas atividades que integram a estrutura produtiva.

Nestes termos, Giovanini et al. (2016) discute a existência de uma quinta lei de Kaldor. O argumento é de que, conforme as economias se industrializam, passam a fabricar produtos cada vez mais complexos e que demandam maior volume de conhecimento. $\mathrm{O}$ desenvolvimento de serviços intermediários, especializados em conhecimento, viabiliza produtos industriais cada vez mais intensivos em tecnologia. Defende-se, então, a hipótese de que a fabricação de produtos mais complexos pela indústria depende do setor de serviços, o qual fornece insumos de produção.

Para os autores, a terceirização de atividades tecnológicas e produtivas a ofertantes de serviços especializados estimula o crescimento do próprio setor, aumentando a produtividade e incentivando a criação de novos serviços. O resultado é um ciclo virtuoso entre terceirização, especialização, produtividade e crescimento, reduzindo os preços dos serviços, aumentando a produtividade industrial e, assim, ampliando a competitividade das economias. Além disso, à medida que a economia se desenvolve, passa a fabricar produtos industriais mais complexos que demandam mais conhecimento, o qual é suprido pelas atividades especializadas de serviços.

Deste modo, é aprofundada a relação de interdependência entre serviços e indústria, em que o crescimento e especialização do primeiro viabiliza a diversificação industrial em direção a atividades mais complexas e que demandam ainda mais serviços. Assim, apenas economias que 
conseguem criar condições adequadas para a vinculação do conhecimento necessário ao processo produtivo continuariam aumentando o seu nível de renda até patamares mais elevados. Considerando que as atividades de serviços fornecem o conhecimento demandado pelo setor industrial, o grau de desenvolvimento dos serviços determina o nível de sofisticação tecnológica da indústria, explicando diferentes níveis e crescimentos da renda (GIOVANINI et al., 2016).

Por último, vale ressalvar que economias desenvolvidas e em desenvolvimento tendem a apresentar muitas disparidades em termos da composição do setor entre serviços tradicionais e modernos. Economias desenvolvidas possuem, no geral, setor mais maduro e serviços mais modernos, intensivos em tecnologia, capital e mão de obra qualificada. Em contrapartida, nas economias em desenvolvimento, de uma maneira geral, o setor envolve maior participação dos serviços tradicionais, de baixo conteúdo tecnológico e que empregam mão de obra menos qualificada. Assim, a técnica e o tipo de mão de obra empregadas nas atividades de serviços diferenciam as economias e seus níveis de desenvolvimento (CARDOSO; PEROBELLI, 2013).

\subsection{Evidências empíricas: efeitos da indústria e dos serviços sobre o crescimento}

Em termos empíricos, diversos trabalhos apontam resultados consistentes com a hipótese da indústria como motor do crescimento econômico (engine of growth hypothesis). $\mathrm{Na}$ literatura internacional, Rodrik (2009), por exemplo, mostra evidências de que a expansão da participação industrial no produto e emprego é positivamente relacionada ao crescimento da renda ao longo do tempo, sendo os países que mais cresceram aqueles que fizeram rápida mudança estrutural de atividades de baixa produtividade (tradicionais) para as de alta produtividade (modernas).

Naudé e Szirmai (2012) também defendem que a transformação estrutural de atividades primárias para industriais de alta produtividade é um condicionante do crescimento econômico, mas ressaltam que tal mudança requer que os países em desenvolvimento estimulem um setor indu strial que ofereça empregos de alta qualidade. Os autores mostram que, depois de 1950, as taxas de crescimento do PIB per capita nas economias em desenvolvimento variaram de $5 \%$ a $9 \%$ ao ano e o crescimento do PIB variou de $6 \%$ a 11,5\%, sendo que, com exceção da Rússia, todos os exemplos de catching-up estão associados ao desenvolvimento do setor industrial.

Vieira et al. (2014) avaliam, por de meio estimações em painel, os efeitos da participação da indústria total e de transformação no PIB e no emprego para explicar a taxa de crescimento da renda de 82 países desenvolvidos e em desenvolvimento entre 1970 e 2009. Os resultados sinalizam a existência de relações positivas entre as participações industriais no PIB e no emprego e o crescimento de longo prazo, sendo os efeitos maiores nas economias em desenvolvimento.

Tregenna (2015) também identifica relações positivas entre as participações da indústria no PIB e no emprego e o crescimento do PIB per capita da década subsequente para países em desenvolvimento no período 1970 a 2010 . Contudo, os resultados são inconclusivos quando os países são agrupados em diferentes períodos e regiões. De 1970 a 2000, observa-se uma relação positiva entre a participação da indústria e o crescimento; mas, de 2000 a 2010, tal relação se torna negativa, o que sugere queda da importância da indústria como motor do crescimento.

As análises por regiões, por sua vez, não resultam em evidências claras dos impactos da indústria sobre o crescimento. Tregenna (2015) atribui tal fato a possíveis diferenças setoriais não observadas entre os países. Ademais, assinala que se as atividades industriais em declínio forem tecnologicamente mais avançadas e capazes de gerarem retornos crescentes de escala e aumentos de produtividade cumulativos superiores às atividades não industriais em expansão (serviços), a perda de participação industrial se mostra atrelada a menores taxas de crescimento.

Com dados brasileiros, também há evidências empíricas favoráveis à hipótese da indústria como motor do crescimento. Marquetti et al. (2005), por exemplo, averiguam os determinantes do crescimento dos municípios do estado do Rio Grande do Sul no período 1990 de 1999, divididos em microrregiões. Os resultados sinalizam que maior especialização em atividades industriais ou agrícolas resulta em maior crescimento. Contudo, a microrregião com maior crescimento apresenta, dentre outros fatores, maior especialização industrial. Já para os estados brasileiros, Vieira et al. 
(2016) estimam modelos em painel com dados de 1992 a 2009, constatando efeitos médios positivos de medidas de participação industrial sobre as taxas estaduais de crescimento.

Outra parte da literatura empírica avalia a contribuição dos serviços para o crescimento. Dasgupta e Singh (2006) investigam os papéis da manufatura, dos serviços e da agricultura para 48 países em desenvolvimento no período de 1990 a 2000, usando uma análise kaldoriana em termos da contribuição setorial para o crescimento do PIB e da produtividade. Os resultados indicam que a manufatura é importante para o crescimento, mas os serviços em geral e específicos, sobretudo os relacionados à tecnologia da informação e comunicação (TIC), têm contribuição positiva mais elevada em grande parte dos países em desenvolvimento, com destaque para a Índia. Segundo os autores, os serviços podem substituir ou complementar as atividades manufatureiras na indução do crescimento. No caso da Índia, a supremacia em TIC pode ajudá-la a avançar tecnologicamente e realizar catching-up com as economias avançadas.

Timmer e de Vries (2009) também ressaltam a importância dos serviços para explicar as acelerações e desacelerações do crescimento em uma amostra de 19 países da Ásia e América Latina no período de 1950 a 2005. Os autores realizam uma análise de shift-share com dados de emprego e valor adicionado na agricultura, indústria, serviços e governo para decompor o crescimento do PIB por trabalhador. As evidências sinalizam que a aceleração do crescimento não é explicada pela realocação de recursos entre setores, mas pela melhoria de produtividade dentro dos setores, sobretudo na indústria e nos serviços, sendo que o último setor parece ser a principal fonte do crescimento nos países desde os anos 1950. Tais evidências contrastam com a visão tradicional de Baumol (1967) sobre o baixo crescimento da produtividade dos serviços.

Szirmai e Verspagen (2011), ao considerarem 55 países para o período de 1960 a 2005, encontram evidências de efeitos médios positivos da participação da indústria de transformação sobre o crescimento, mas não da participação dos serviços. Porém, analisando os subperíodos de 1960 a 1970, 1970 a 1990 e 1990 a 2005, apenas no segundo subperíodo há indícios tanto de efeitos positivos da indústria como dos serviços sobre o crescimento. Tal resultado sinaliza que, desde os anos 1990, a manufatura perde força para estimular o crescimento e promover o catching-up, com poucos benefícios para países de níveis intermediários de desenvolvimento.

Park e Shin (2012) investigam as perspectivas dos serviços como fonte de crescimento nos 12 países da Ásia. Análises das participações da agricultura, indústria e serviços sugerem que os últimos contribuem mais para o avanço do PIB per capita, especialmente nos países em que o setor é maior, como Índia e Paquistão. Ademais, alguns países asiáticos apresentam taxas de aumento da produtividade nos serviços superiores às da indústria. Outro resultado é que o aumento da produtividade do trabalho nos serviços é maior em países com menores níveis de PIB. Portanto, as evidências sinalizam papel importante dos serviços no crescimento da Ásia.

CNI (2014) averigua se o desenvolvimento industrial (medido pela densidade industrial) está atrelado à participação dos serviços comerciais no PIB em 19 países desenvolvidos e em desenvolvimento para os anos de 1995 a 2005, obtendo forte correlação positiva entre os dois indicadores. Ademais, sinaliza que a contribuição dos serviços comerciais no valor da produção setorial aumenta segundo a intensidade tecnológica, sendo maior nos países desenvolvidos, que concentram serviços que agregam mais valor, ao contrário de países em desenvolvimento, nos quais ainda predominam serviços de baixo custo (mão de obra menos qualificada e barata).

Nessa linha, Giovanini et al. (2016) testam a hipótese da quinta lei de Kaldor com dados de 8 países desenvolvidos no período de 1980 a 2009, verificando se: i) o crescimento do valor adicionado do setor de serviços explica o crescimento da densidade do setor industrial; e ii) o aumento da complexidade econômica explica a elevação do valor adicionado dos serviços. Os resultados encontrados corroboram a hipótese, apontando que crescimento dos serviços explica aumentos da produtividade industrial e da complexidade econômica (produtos industriais com maior sofisticação tecnológica). Isso indica que países em desenvolvimento deveriam adotar políticas voltadas simultaneamente para os setores industrial e de serviços intermediários para promover a produção de bens industriais mais sofisticados e, assim, estimular o crescimento. 
Avaliando a dinâmica da economia brasileira no período de 1996 a 2009, Jacinto e Ribeiro (2015) mostram que a evolução da produtividade dos serviços foi positiva, contrastando com a queda da produtividade industrial. Assim, os autores obtêm evidências contrárias à existência de "doença de custos" no Brasil. Verifica-se também que a composição dos serviços é heterogênea e que os serviços prestados às empresas tiveram aumento de produtividade, descartando a explicação do baixo desempenho da produtividade da indústria pela mudança estrutural da economia para os serviços. Observa-se, ainda, que a evolução da produtividade dos dois setores foi, no geral, explicada pelo comportamento intra-setorial. Nos serviços, o indicador foi positivamente afetado pela realocação de mão de obra para setores mais produtivos, ao contrário da indústria.

Nessa direção, Silva et al. (2016), analisando dados de 2007 a 2013, verificam crescimento de $58 \%$ no número de empresas e de 50\% no número de pessoal ocupado no setor de serviços brasileiro. Os serviços prestados às famílias e os serviços de manutenção e reparação (atividades destinadas ao consumidor final) apresentaram níveis de produtividade e salários relativamente baixos no período. Por outro lado, os serviços de informação e comunicação tiveram elevados níveis de produtividade e de salários. As últimas atividades são mais intensivas em capital e tecnologia e são mais ligadas ao consumo intermediário. Também se verifica que os serviços mais intensivos em conhecimento possuíram maiores níveis de produtividade e de salários.

Em suma, as evidências da literatura empírica sobre a hipótese do motor do crescimento econômico apresentam uma evolução semelhante à teórica no que diz respeito ao papel do setor de serviços. No geral, a importância industrial na promoção do crescimento ainda é defendida, contudo, a indústria parece ter reduzido tal relevância no período mais recente e nas economias desenvolvidas, com estágios de industrialização mais avançados. Nestes casos, considera-se que os serviços, especialmente os dotados de maior conhecimento e intensidade tecnológica, possam se tornar o setor motor do crescimento. Já nas economias em desenvolvimento, parece haver um papel mais relevante da industrialização para o estímulo ao crescimento econômico.

\section{Estratégias empíricas e dados}

\subsection{Método e modelos}

Para atingir o objetivo do estudo, são realizadas estimações em painel com efeitos fixos (errospadrão robustos) - regressões por Mínimos Quadrados Ordinários nas quais as variáveis são consideradas como desvios em relação às médias (estimador Within) para controlar efeitos fixos. Para averiguar a melhor adequação deste método em comparação ao de efeitos aleatórios - Mínimos Quadrados Generalizados - são realizados, para todas as especificações, o teste de Hausman. Se a estatística resultante for significativa, os efeitos fixos são mais adequados².

Para investigar qual setor (indústria ou serviços) afeta mais o crescimento econômico dos municípios brasileiros, são estimados modelos baseados nas equações (1) e (2). As estimações são feitas para todos os municípios com dados disponíveis para o período de 1999 a $2012^{3}$, bem como para os municípios segmentados segundo o PIB per capita médio no período. Tal variável é usada para ordenar os municípios e identificar os quintis da distribuição, a partir dos quais são divididos em 3 grupos: i) "PIB Baixo" ( $1^{\circ}$ quintil); ii) "PIB Intermediário" ( $2^{\circ}, 3^{\circ}$ e $4^{\circ}$ quintis $)$; e iii) "PIB Alto" (50 quintil). Assim, é averiguado se os resultados se alteram entre os municípios com diferentes níveis de renda (efeitos heterogêneos), em consonância com evidências da literatura (subseção 2.2) de que os efeitos da indústria e dos serviços podem ser distintos entre economias com diferentes níveis de desenvolvimento (no geral, medido pelo nível de renda per capita).

$$
\Delta Y_{i t, t+5}=\alpha_{0}+\alpha_{1} I n d / P I B_{i t}+\alpha_{2} \operatorname{Serv} / P I B_{i t}+\alpha_{3} Z_{i t}+\alpha_{4} T_{t}+\mu_{i}+\varepsilon_{i t}
$$

\footnotetext{
${ }^{2}$ Para mais detalhes sobre os aspectos metodológicos, ver: Baltagi (2001) e Wooldridge (2002), entre outros.

${ }^{3} \mathrm{O}$ período foi escolhido exclusivamente em função da disponibilidade dos dados necessários.
} 
$\Delta Y_{i t, t+5}=\alpha_{0}+\alpha_{5}$ Ind_Serv $/ P I B_{i t}+\alpha_{6}$ Ind $/$ Ind_Serv $v_{i t}+\alpha_{3} Z_{i t}+\alpha_{4} T_{t}+\mu_{i}+\varepsilon_{i t}$

sendo: $\Delta Y_{i t, t+5}$ a variável dependente; $\alpha_{0}$ a constante; Ind $/ P I B_{i t}, \operatorname{Serv} / P I B_{i t}$, Ind_Serv $/ P I B_{i t} \mathrm{e}$ Ind/Ind_Serv ${ }_{i t}$ as variáveis explicativas de interesse para o estudo; $\alpha_{1}, \alpha_{2}, \alpha_{5}$ e $\alpha_{6}$ os coeficientes estimados associados a elas; $Z_{i t}$ um vetor de variáveis de controle (covariadas); $\alpha_{3}$ vetor de coeficientes estimados associados às covariadas; $T_{t}$ o vetor de dummies anuais (1999 é o default); $\alpha_{4}$ $\mathrm{o}$ vetor de coeficientes associados às dummies; $\mu_{i}$ os efeitos fixos; e $\varepsilon_{i t} \mathrm{o}$ erro.

A variável dependente crescimento econômico $\left(\Delta Y_{i t, t+5}\right)$ corresponde à taxa média anual do crescimento do PIB per capita real do município $i$ no quinquênio subsequente a $t$, sendo 2000 o anobase e o deflator implícito do PIB o indicador para deflacionar os dados. Assim, as estimações abrangem crescimentos até 2012, mas as variáveis explicativas vão até 2007, último ano para o qual é possível calcular taxas para 5 anos posteriores, pois há dados disponíveis de PIB municipais apenas até 2012. A opção por taxas para 5 anos segue a literatura, que considera um período adequado para avaliar crescimento no longo prazo. Já a opção por mensurar efeitos no tempo de variáveis em anos anteriores pode suavizar problemas de endogeneidade (BARRO, 1990; DEVARAJAN et al., 1996; ROCHA; GIUBERTI, 2007). Szirmai e Verspagen (2011) fazem as mesmas opções para algumas análises similares às deste estudo com dados de países.

Os dados para o cálculo das taxas de crescimento econômico municipais são oriundos do Instituto Brasileiro de Geografia e Estatística (IBGE). Este também disponibiliza informações sobre a composição dos PIBs municipais em valores adicionados (VAs) de quatro setores: indústria ${ }^{4}$, serviços, agropecuária e setor público (administração, saúde e educação públicas e seguridade social). Por meio destas informações são calculadas as quatro variáveis explicativas de interesse para o presente estudo. A primeira é denominada como indústria/PIB e representada na equação (1) por Ind/PIB $B_{i t}$. Trata-se da razão entre o VA da indústria e PIB municipal. A segunda, chamada de serviços/PIB e representada por $\operatorname{Serv} / P I B_{i t}$, é a razão entre o VA dos serviços e o PIB. A comparação entre os coeficientes estimados associados a estas variáveis - respectivamente, $\alpha_{1}$ e $\alpha_{2}$ - sinaliza qual destes dois setores, relativamente aos demais, gera maior crescimento.

Participações dos VAs da indústria e dos serviços no PIB são medidas tradicionalmente empregadas pela literatura para averiguar os impactos destes setores no crescimento (RODRIK, 2009; PARK; SHIN, 2012; VIEIRA et al., 2014; TREGENNA, 2015). No presente estudo, são propostas duas medidas adicionais para garantir maior robustez, principalmente para a possível heterogeneidade dos efeitos por níveis distintos de PIB per capita. Estas são representadas na equação (2). A primeira, chamada de indústria+serviços/PIB (Ind_Serv/PIB $B_{i t}$ ), corresponde à participação conjunta dos VAs da indústria e dos serviços no PIB. O intuito é reforçar se estes setores são ou não os motores do crescimento comparativamente aos demais (agropecuária e público). A segunda, denominada como indústria/(indústria+serviços) (Ind/Ind_Serv ${ }_{i t}$ ), é a participação do VA da indústria no somatório dos VAs da própria indústria e dos serviços. O objetivo é avaliar qual dos dois serviços comparativamente ao outro gera mais crescimento.

Para os municípios brasileiros, é pouco explorada pela literatura empírica a possibilidade de especialização ou diversificação da economia entre os setores afetar o crescimento. Na primeira seção, são apontadas as poucas evidências existentes. Neste estudo, uma avaliação desse tipo é realizada focando a especialização/diversificação entre a indústria e os serviços. Conforme foi apontado na introdução, a diversificação pode favorecer o crescimento devido à interdependência entre os dois setores e à possível "suavização" de crises de um setor pelo outro. Por outro lado, maior especialização pode resultar em ganhos de produtividade benéficos ao crescimento. Para averiguar tais aspectos, são estimados modelos baseados na equação (3).

$\Delta Y_{i t, t+5}=\alpha_{0}+\alpha_{5}$ Ind_Serv $/ P I B_{i t}+\alpha_{7} E s p_{i t}+\alpha_{3} Z_{i t}+\alpha_{4} T_{t}+\mu_{i}+\varepsilon_{i t}$

${ }^{4}$ Infelizmente os dados oferecidos pelo IBGE para municípios se referem à atividade industrial como um todo, não permitindo a realização de uma análise específica para a indústria de transformação (manufatureira). 
Em (3), $E s p_{i t}$ representa a variável especialização indústria ou serviços, que é a medida do grau de especialização (ou concentração ou diversificação) da produção municipal entre a indústria e os serviços usada neste estudo. Trata-se de uma adaptação do coeficiente de Gini-Hirschmann, que normaliza para o intervalo de 0 e 1 a raiz quadrada do índice Hirschmann-Herfindahl, uma das medidas tradicionais de concentração. Essa variável é calculada da maneira expressa pela equação (4). Ou seja, pela raiz quadrada do somatório das participações dos VAs da indústria e dos serviços no somatório destes VAs - respectivamente, $(\text { Ind/Ind_Serv } i t)^{2}$ e $\left(\operatorname{Ser} / \text { Ind_Serv } v_{i t}\right)^{2}$. Controlando pela variável indústria+serviços/PIB (Ind_Serv/PIB $B_{i t}$ ) -participação conjunta dos VAs da indústria e dos serviços no PIB -, quanto maior o valor da variável de especialização indústria ou serviços, mais especializada (menos diversificada) é a produção do município em um dos setores; quanto menor o valor, menor a especialização.

$E s p_{i t}=\left[\left(\text { Ind } / \text { Ind_Serv }{ }_{i t}\right)^{2}+\left(\operatorname{Serv} / \operatorname{Ind} \_\operatorname{Serv}{ }_{i t}\right)^{2}\right]^{1 / 2}$

Como também mencionado na introdução, outra hipótese testada neste estudo é a de que os efeitos das participações setoriais sobre o crescimento também podem ser heterogêneos de acordo com a importância do próprio setor para a economia. Para averiguar tal fato, é aqui levantada a possibilidade dos efeitos médios das participações da indústria e dos serviços não serem lineares; ou seja, dos sinais dos coeficientes estimados a eles associados se alterarem a partir de dada participação. A proposta aqui feita para averiguar tal hipótese é estimar modelos baseados nas equações (5) e (6), nas quais as participações dos VAs da indústria e dos serviços, respectivamente, são consideradas em uma forma funcional quadrática (polinômio de $2^{\circ}$ grau).

$$
\begin{aligned}
& \Delta Y_{i t, t+5}=\alpha_{0}+\alpha_{1} \text { Ind } / P I B_{i t}+\alpha_{8}\left(\text { Ind } / P I B_{i t}\right)^{2}+\alpha_{2} \operatorname{Serv} / P I B_{i t}+\alpha_{3} Z_{i t}+T_{t}+\mu_{i}+\varepsilon_{i t} \\
& \Delta Y_{i t, t+5}=\alpha_{0}+\alpha_{1} \text { Ind } / P I B_{i t}+\alpha_{2} \operatorname{Serv} / P I B_{i t}+\alpha_{9}\left(\operatorname{Serv} / P I B_{i t}\right)^{2}+\alpha_{3} Z_{i t}+T_{t}+\mu_{i}+\varepsilon_{i t}
\end{aligned}
$$

Em (5) ou (6), se o coeficiente estimado associado à participação do setor analisado em nível $\left(\alpha_{1}\right.$ ou $\left.\alpha_{2}\right)$ for significativo e positivo e o coeficiente da participação ao quadrado $\left(\alpha_{8}\right.$ ou $\left.\alpha_{9}\right)$ for significativo e negativo, é sinalizada relação entre participação do setor e crescimento econômico em formato próximo a um "U-invertido". Assim, a taxa de crescimento aumenta à medida que a participação do setor no PIB se eleva; porém, atingida determinada participação, a taxa de crescimento diminui. Por outro lado, se os coeficientes forem significativos, negativo em nível e positivo ao quadrado, constata-se relação próxima a um "U": a taxa de crescimento diminui à medida que a participação do setor aumenta, mas, atingida dada participação, passa a aumentar. No caso do "U-invertido", há um turning point que denota um ponto de máximo; no caso do "U”, o turning point representa um ponto de mínimo. Para as estimações baseadas em (5) e (6), os turning points são calculados segundo, respectivamente, as equações (7) e (8).

$$
\begin{aligned}
& \overline{\operatorname{Ind}} / P I B=-\frac{\alpha_{1}}{2 \alpha_{8}} \\
& \overline{\operatorname{Serv}} / P I B=-\frac{\alpha_{2}}{2 \alpha_{9}}
\end{aligned}
$$

Nos modelos discutidos até o momento, são inseridas variáveis de controle (covariadas), representadas nas equações pelo termo $Z_{i t}$, que correspondem a características observadas dos municípios variantes no tempo que, de acordo com diferentes correntes da literatura econômica, podem influenciar o crescimento econômico. Estas covariadas são apresentadas no Quadro 1. O controle pelo PIB per capita é justificado pela hipótese de convergência da renda, que advoga uma relação negativa entre o nível inicial de renda e a sua taxa de crescimento. Tal hipótese é originária do modelo neoclássico de crescimento de Solow (1956), sendo averiguada em vários trabalhos, tais como Barro e Sala-i-Martin (1992, 1997), Baumol (1986) e Baumol e Wolfe (1988).

Outro aspecto oriundo do modelo de Solow (1956) é a necessidade de considerar a taxa de crescimento da população para investigar o crescimento econômico, dado que um aumento populacional tende a diminuir o produto per capita. Já em modelos de crescimento endógeno, 
defende-se que a expansão de população pode gerar crescimento se for acompanhada por mais pesquisadores e, assim, avanços tecnológicos (OLIVEIRA, RODRIGUES JÚNIOR, 2011).

Os modelos de crescimento endógeno enfatizam a importância do capital humano para o crescimento econômico, principalmente devido a ganhos de produtividade dos trabalhadores (MANKIW et al.,1992). Na ausência de outra informação para todos os anos e municípios aqui analisados, a proxy para capital humano é a variável ensino médio, calculada por meio de dados da Relação Anual de Informações Sociais (RAIS) do Ministério do Trabalho e Emprego (MTE). Devese ressalvar que tal proxy pode não ser a mais adequada, principalmente em comparação a anos de estudos médios, que é a mais utilizada na literatura, mas é a possível de ser calculada.

Quadro 1 - Variáveis de controle (covariadas) $Z_{i t}$ : descrições e fontes

\begin{tabular}{|c|c|c|}
\hline Variáveis & Descrições & Fontes \\
\hline PIB per capita & Produto Interno Bruto real per capita (R\$ milhares de 2000) & IBGE \\
\hline Crescimento da População & Taxa de crescimento médio da população para 5 anos & IBGE \\
\hline Ensino Médio & Empregados com ensino médio ou mais / vínculos formais totais & MTE \\
\hline Gastos Públicos & Despesas públicas totais (R\$ bilhões de 2000) & STN \\
\hline Investimentos/Gastos & Investimentos / despesas públicas totais & STN \\
\hline Arrecadação/Receita & Arrecadação tributária própria / receitas públicas totais & STN \\
\hline
\end{tabular}

Observações: MTE - Ministério do Trabalho e Emprego; STN - Secretaria do Tesouro Nacional.

O papel dos gastos públicos para o crescimento é um dos principais debates econômicos. Algumas correntes dão maior peso a tal papel, outras menos. Porém, no geral, aponta-se que os gastos públicos (política fiscal expansionista) induzem o crescimento no curto e/ou longo prazo. Em alguns trabalhos, como Barro (1990), Devarajan et al. (1996) e Rocha e Giuberti (2007), é discutida a importância da composição das despesas, sendo que algumas categorias podem ser mais "produtivas" ou se tornarem "improdutivas" em níveis não ideais. Os investimentos são quase sempre defendidos como uma categoria "produtiva" (ASCHAUER, 1989; EASTERLY; REBELO, 1993). Tal fato justifica a inclusão da covariada investimentos/gastos nos modelos.

Para os municípios brasileiros, Mendes (2005) mostra que quanto maior as transferências recebidas dos estados e União, maior tende a ser a captura de recursos pelos governantes, o que é atribuído a uma ilusão fiscal por se tratam de recursos que, pelo menos em parte, não são cobrados diretamente dos residentes. Assim, é plausível supor que quanto maior a dependência municipal de arrecadação tributária própria para financiar suas políticas, melhor tende a ser a eficácia e eficiência destas, pois a população percebe que está pagando e, consequentemente, exerce maior o controle social. Deve-se considerar, ainda, que parte da arrecadação tributária municipal advém do Imposto Predial e Territorial Urbano (IPTU). Segundo Marques Júnior et al. (2006), tributos sobre a propriedade, apesar de aumentarem custos da terra, não impactam diretamente sobre a acumulação de capital físico e humano, resultando em pequenos efeitos distorcidos na economia. Tais argumentos justificam a covariada arrecadação/receitas. Esta variável e as de gastos são calculadas com dados da Secretaria do Tesouro Nacional (STN).

Por último, deve-se apontar que, além das características municipais observadas variantes no tempo - covariadas $Z_{i t}$ - e características não observadas diferentes entre os municípios e constantes no tempo - efeitos fixos $\left(\mu_{i}\right)$-, são controlados, por dummies anuais (1999 como default), os efeitos de características não observadas fixas entre os municípios e variantes no tempo. Estas controlam, por exemplo, mudanças institucionais e aspectos macroeconômicos.

\subsection{Estatísticas descritivas e evolução da composição setorial média dos municípios}

Na sequência, são feitas algumas análises descritivas que contribuem para a interpretação dos resultados na próxima seção e, ao mesmo tempo, caracterizam a composição setorial média do 
produto e sua evolução nos municípios brasileiros (total e por faixas de PIB per capita), o que, mesmo fugindo do escopo do estudo, pode garantir evidências adicionais para a literatura.

Primeiramente, a Tabela 1 mostra médias e desvios-padrão de todas as variáveis utilizadas nas estimações no período considerado - 1999 a 2007 para as variáveis explicativas e 1999 a 2012 para a variável dependente (crescimento econômico). Em relação à última, observa-se que o crescimento médio é positivo nas quatro amostras. Assim, nas análises dos resultados, efeitos médios positivos associados às variáveis explicativas devem ser entendidos como aumentos do crescimento em relação à média; efeitos médios negativos como reduções em relação à média.

Tabela 1 - Variáveis: médias e desvios-padrão, segundo as faixas de PIB per capita médio (1999 a 2007)

\begin{tabular}{c|c|c|c|c|c|c|c|c}
\hline Variáveis / Faixas de PIB / & \multicolumn{2}{|c|}{ Brasil } & \multicolumn{2}{c|}{ PIB Baixo } & \multicolumn{2}{c|}{ PIB Intermediário } & \multicolumn{2}{c}{ PIB Alto } \\
\cline { 2 - 8 } Estatísticas & Média & D.P. & Média & D.P. & Média & D.P. & Média & D.P. \\
\hline Crescimento Econômico & 0,05 & 0,08 & 0,04 & 0,05 & 0,04 & 0,06 & 0,06 & 0,12 \\
Indústria/PIB & 0,15 & 0,13 & 0,09 & 0,04 & 0,13 & 0,10 & 0,25 & 0,19 \\
Serviços/PIB & 0,55 & 0,14 & 0,67 & 0,09 & 0,56 & 0,12 & 0,43 & 0,14 \\
(Indústria+Serviços)/PIB & 0,70 & 0,15 & 0,76 & 0,10 & 0,69 & 0,14 & 0,68 & 0,18 \\
Indústria/(Indústria+Serviços) & 0,20 & 0,14 & 0,12 & 0,05 & 0,18 & 0,11 & 0,33 & 0,20 \\
Especialização Indústria ou Serviços & 0,85 & 0,07 & 0,89 & 0,03 & 0,85 & 0,06 & 0,80 & 0,08 \\
PIB per capita & 4,52 & 5,19 & 1,39 & 0,34 & 3,64 & 1,69 & 10,26 & 9,02 \\
Crescimento da População & 0,01 & 0,03 & 0,01 & 0,03 & 0,01 & 0,03 & 0,01 & 0,03 \\
Ensino Médio & 0,28 & 0,14 & 0,37 & 0,19 & 0,27 & 0,12 & 0,24 & 0,09 \\
Gastos Públicos & 0,02 & 0,15 & 0,01 & 0,01 & 0,01 & 0,03 & 0,05 & 0,32 \\
Investimentos/Gastos & 0,11 & 0,07 & 0,11 & 0,08 & 0,11 & 0,07 & 0,12 & 0,07 \\
Arrecadação/Receita & 0,06 & 0,06 & 0,02 & 0,02 & 0,05 & 0,05 & 0,09 & 0,08 \\
\hline
\end{tabular}

Fontes: IBGE, MTE e STN. Elaboração própria. Observação: D.P. - desvios-padrão.

As participações da indústria e dos serviços são discutidas com mais detalhes mais abaixo. Aqui deve-se destacar que, em conjunto - (indústria+serviços)/PIB -, os VAs dos dois setores são responsáveis, em média, por $70 \%$ dos PIBs municipais, percentual que varia de $68 \%$ nos municípios de "PIB Alto" a 76\% nos de "PIB Baixo". No somatório dos VAs dos dois setores, a indústria não ultrapassa, em nenhuma das quatro amostras, uma participação superior a $33 \%$ indústria/(indústria+serviços). $\mathrm{Na}$ média, o indicador de especialização indústria ou serviços diminui conforme se eleva a faixa de PIB per capita médio, o que sinaliza que municípios com menores rendas têm maior especialização da produção em um dos setores. Os PIBs per capita médios mostram como são discrepantes os grupos de municípios, variando de R \$1.390 nos de "PIB Baixo" a R \$10.260 nos de "PIB Alto". Discrepâncias no mesmo sentido são observadas na arrecadação/receita, o que está de acordo com evidências da literatura de maior capacidade de arrecadação própria nos municípios com rendas maiores (GOMES; MACDOWELL, 2000).

A Tabela 2 mostra as evoluções das participações médias dos VAs setoriais nos PIBs dos municípios de 1999 a 2007, para o Brasil como um todo e para as amostras por faixas de PIB per capita médio. Até esse momento e nas estimações, as participações são medidas em razões, mas, na Tabela 2, optou-se por reportá-las em percentuais para facilitar as análises. Observa-se que, no total, a participação dos serviços é a mais relevante, com média de $56,82 \%$ no período, seguida pela indústria $(24,12 \%)$, setor público $(13,83 \%)$, e, por último, agropecuária $(5,23 \%)$. Apenas os serviços perderam participação no PIB no período (queda de 4,14\%). A agropecuária manteve-se praticamente estável (aumento de 0,29\%); já o setor público e a indústria tornaram-se mais representativos nos PIBs municipais, com aumentos de, respectivamente, $8,97 \%$ e $5,77 \%$.

A análise por municípios segmentados por faixas de PIB per capita médio aponta padrões diferentes para as contribuições dos VAs setoriais. Em todas as faixas, os serviços são os mais relevantes, sendo sua participação relativamente maior nos municípios de "PIB Baixo" (média de $65,46 \%$ ), com variação positiva no período (aumento de 1,38\%). Nos demais municípios, o setor perde participação, sobretudo naqueles de "PIB Ato", cujo decrescimento atinge 5,19\%.

A indústria tem maior peso nos municípios de "PIB Alto" (média de 26,44\%), refletindo o maior grau de industrialização destes, com aumento da participação em 7,03\% no período. Nos 
municípios de "PIB Intermediário", a indústria contribui com, em média, 18\% do PIB. Nos municípios de "PIB Baixo", a contribuição é a mais baixa (média de 10,36\%), sendo que, nas duas faixas, a participação industrial se manteve relativamente estável (aumento inferior a 2\%).

Tabela 2 - Evolução das participações médias (\%) dos VAs dos setores econômicos no PIB dos municípios brasileiros, segundo faixas de PIB per capita médio (1999 a 2007)

\begin{tabular}{|c|c|c|c|c|c|c|c|c|c|c|c|}
\hline Setor / Ano & 1999 & 2000 & 2001 & 2002 & 2003 & 2004 & 2005 & 2006 & 2007 & Média & $\Delta \%$ \\
\hline \multicolumn{12}{|c|}{ Brasil } \\
\hline Indústria & 22,60 & 24,02 & 23,13 & 23,30 & 24,09 & 25,84 & 25,12 & 24,69 & 23,91 & 24,12 & 5,77 \\
\hline Serviços & 59,75 & 57,74 & 57,65 & 57,14 & 56,03 & 54,05 & 55,78 & 56,46 & 57,28 & 56,82 & $-4,14$ \\
\hline Agropecuária & 4,77 & 4,85 & 5,13 & 5,70 & 6,39 & 5,93 & 4,90 & 4,71 & 4,78 & 5,23 & 0,29 \\
\hline Público & 12,88 & 13,38 & 14,09 & 13,85 & 13,49 & 14,18 & 14,20 & 14,14 & 14,03 & 13,83 & 8,97 \\
\hline \multicolumn{12}{|c|}{ PIB Baixo } \\
\hline Indústria & 10,50 & 10,01 & 10,21 & 9,83 & 9,70 & 10,46 & 10,84 & 10,84 & 10,69 & 10,36 & 1,81 \\
\hline Serviços & 66,47 & 65,03 & 65,22 & 64,25 & 63,50 & 64,21 & 66,31 & 66,36 & 67,38 & 65,46 & 1,38 \\
\hline Agropecuária & 20,28 & 22,33 & 21,52 & 22,62 & 23,41 & 21,85 & 19,20 & 18,97 & 18,24 & 20,83 & $-10,09$ \\
\hline Público & 2,75 & 2,62 & 3,05 & 3,31 & 3,38 & 3,49 & 3,65 & 3,83 & 3,69 & 3,34 & 34,29 \\
\hline \multicolumn{12}{|c|}{ PIB Intermediário } \\
\hline Indústria & 18,01 & 18,52 & 17,92 & 18,01 & 18,01 & 19,62 & 19,16 & 18,58 & 18,08 & 18,45 & 0,38 \\
\hline Serviços & 62,68 & 61,60 & 61,39 & 60,45 & 59,14 & 58,42 & 60,21 & 60,78 & 61,68 & 60,67 & $-1,60$ \\
\hline Agropecuária & 10,57 & 10,75 & 10,94 & 11,85 & 13,16 & 12,28 & 10,75 & 10,66 & 10,64 & 11,29 & 0,69 \\
\hline Público & 8,74 & 9,13 & 9,76 & 9,69 & 9,69 & 9,68 & 9,89 & 9,99 & 9,60 & 9,59 & 9,85 \\
\hline \multicolumn{12}{|c|}{ PIB Alto } \\
\hline Indústria & 24,49 & 26,25 & 25,25 & 25,54 & 26,62 & 28,39 & 27,51 & 27,14 & 26,22 & 26,44 & 7,03 \\
\hline Serviços & 58,57 & 56,25 & 56,16 & 55,78 & 54,74 & 52,27 & 54,01 & 54,73 & 55,53 & 55,26 & $-5,19$ \\
\hline Agropecuária & 2,38 & 2,40 & 2,71 & 3,07 & 3,54 & 3,33 & 2,54 & 2,29 & 2,46 & 2,74 & 3,46 \\
\hline Público & 14,56 & 15,10 & 15,87 & 15,61 & 15,10 & 16,01 & 15,94 & 15,84 & 15,80 & 15,56 & 8,48 \\
\hline
\end{tabular}

Fontes: IBGE. Elaboração própria. Observação: $\Delta \%$ - variação percentual de 1999 a 2007.

No caso da agropecuária, verifica-se maior dependência dos municípios de "PIB Baixo" em relação ao desempenho deste setor, visto que sua participação corresponde, na média, a 20,83\% do PIB, embora tenha reduzido (10\%) no período. Os dados da Tabela 2 sugerem, ainda, que a participação da agropecuária diminui à medida que aumenta o PIB, sendo que a participação média nos municípios aqui classificados como de "PIB Alto" é inferior a 3\%. Em relação ao setor público, deve-se destacar: i) avanço da sua participação no período em todas as faixas de PIB; ii) participação significativamente maior nos municípios de "PIB Alto" (média de 15,5\%); e iii) aparente tendência de aumento do peso à medida que o PIB per capita se eleva.

Por último, vale ressaltar dois aspectos em relação às evidências da Tabela 2. O primeiro é que a maior participação dos serviços no Brasil também é observada em outros trabalhos com diferentes dados, medidas e períodos de análise (CNI, 2014; SILVA et al., 2016). O segundo é que a avaliação da participação setorial por faixas de PIB converge para o padrão internacional apontado por Szirmai e Verspagen (2011). Estes verificam que, em países em desenvolvimento (renda baixa), a participação da agropecuária é relativamente maior do que nos desenvolvidos (renda alta), mas 
declinante no tempo. Já as participações industrial e dos serviços tendem a aumentar nos países em desenvolvimento, embora a indústria não atinja o mesmo peso que nos desenvolvidos. Nestes, a participação dos serviços no PIB também é crescente e a industrial é decrescente. Assim, observam um aumento de longo prazo da participação industrial nos países em desenvolvimento e uma contração nos países desenvolvidos em razão do aumento dos serviços.

\section{Análises dos resultados}

A seguir, são analisados os resultados das estimações. Inicialmente, vale destacar que, em todas as especificações, o teste de Hausman sinaliza a melhor adequação do método de efeitos fixos frente ao de efeitos aleatórios (estatísticas dos testes são significativas). Dessa forma, são reportados somente os resultados obtidos por efeitos fixos. Para não fugir do escopo do estudo, outra opção é não reportar os coeficientes estimados associados às dummies anuais e, em grande parte das especificações, os coeficientes associados aos controles (covariadas), até por estes não variarem muito. Todos os coeficientes não reportados podem ser obtidos junto aos autores.

A Tabela 3 mostra os resultados das estimações que consideram as participações dos VAs. da indústria e dos serviços nos PIBs - respectivamente, indústria/PIB e serviços/PIB. Para a amostra o total, os coeficientes das duas variáveis são positivos e significativos, sendo o dos serviços superior. Tais resultados sugerem que, na média, aumentos das participações da indústria e dos serviços geram maior crescimento, sendo superior o efeito médio dos serviços.

Tabela 3 - Efeitos das participações da indústria e dos serviços sobre o crescimento

\begin{tabular}{|c|c|c|c|c|}
\hline Variáveis / Faixas de PIB & Brasil & PIB Baixo & PIB Intermediário & PIB Alto \\
\hline Indústria/PIB & $\begin{array}{l}0,0147^{*} \\
(0,0068)\end{array}$ & $\begin{array}{c}0,0869 * * * \\
(0,0200)\end{array}$ & $\begin{array}{c}0,0426 * * * \\
(0,0098)\end{array}$ & $\begin{array}{l}-0,0427 * \\
(0,0224)\end{array}$ \\
\hline Serviços/PIB & $\begin{array}{c}0,3299 * * * \\
(0,0073)\end{array}$ & $\begin{array}{l}0,0256^{*} \\
(0,0132)\end{array}$ & $\begin{array}{c}0,1667 * * * \\
(0,0088)\end{array}$ & $\begin{array}{c}0,2646 * * * \\
(0,0236)\end{array}$ \\
\hline PIB per capita & $\begin{array}{c}-0,0123 * * * \\
(0,0002)\end{array}$ & $\begin{array}{c}-0,1195 * * * \\
(0,0032)\end{array}$ & $\begin{array}{c}-0,0396 * * * \\
(0,0006)\end{array}$ & $\begin{array}{c}-0,0108 * * * \\
(0,0003)\end{array}$ \\
\hline Crescimento da População & $\begin{array}{c}-0,3346^{* * * *} \\
(0,0110)\end{array}$ & $\begin{array}{c}-0,2711 * * * \\
(0,0155)\end{array}$ & $\begin{array}{c}-0,2497 * * * \\
(0,0111)\end{array}$ & $\begin{array}{c}-0,2111 * * * \\
(0,0497)\end{array}$ \\
\hline Ensino Médio & $\begin{array}{c}0,0038 \\
(0,0037)\end{array}$ & $\begin{array}{c}0,0019 \\
(0,0035)\end{array}$ & $\begin{array}{c}0,0021 \\
(0,0043)\end{array}$ & $\begin{array}{l}0,0474 * * \\
(0,0226)\end{array}$ \\
\hline Gastos Públicos & $\begin{array}{c}0,0329 * * * \\
(0,0114)\end{array}$ & $\begin{array}{c}0,0231 \\
(0,0562)\end{array}$ & $\begin{array}{c}0,3357 * * * \\
(0,0507)\end{array}$ & $\begin{array}{l}0,0179 * \\
(0,0078)\end{array}$ \\
\hline Investimentos/Gastos & $\begin{array}{c}0,0158 * * * \\
(0,0050)\end{array}$ & $\begin{array}{c}0,0175^{* *} \\
(0,0070)\end{array}$ & $\begin{array}{c}0,0030 \\
(0,0053)\end{array}$ & $\begin{array}{c}0,0385 * * \\
(0,0177)\end{array}$ \\
\hline Arrecadação/Receita & $\begin{array}{c}0,0420 * * * \\
(0,0141)\end{array}$ & $\begin{array}{c}0,0097 \\
(0,0359)\end{array}$ & $\begin{array}{c}0,0528 * * * \\
(0,0153)\end{array}$ & $\begin{array}{l}0,0862 * * \\
(0,0354)\end{array}$ \\
\hline $\begin{array}{l}\text { Dummies Anuais } \\
\text { Constantes }\end{array}$ & $\begin{array}{l}\text { Sim } \\
\text { Sim }\end{array}$ & $\begin{array}{l}\text { Sim } \\
\text { Sim }\end{array}$ & $\begin{array}{l}\text { Sim } \\
\text { Sim }\end{array}$ & $\begin{array}{l}\text { Sim } \\
\text { Sim }\end{array}$ \\
\hline Prob $>F$ & 0,0000 & 0,0000 & 0,0000 & 0,0000 \\
\hline Teste de Hausman & $1100,17 * * *$ & $785,98 * * *$ & $7296,18 * * *$ & $1198,60 * * *$ \\
\hline Observações & 47.163 & 8.880 & 28.572 & 9.711 \\
\hline
\end{tabular}

Erros-padrão robustos entre parênteses. *** Significativo a $1 \%$. ** Significativo a 5\%. * Significativo a $10 \%$.

Avaliando as estimações com amostras segmentadas segundo os PIBs per capita médios, observa-se na Tabela 3 que, nos municípios com "PIB Baixo", os coeficientes associados às variáveis indústria/PIB e serviços/PIB são significativos e positivos, sendo o efeito médio da indústria superior ao dos serviços. Nos municípios com "PIB Intermediário", os coeficientes associados às duas variáveis também são significativos e positivos, mas, assim como na amostra completa, o efeito médio da participação dos serviços é superior ao industrial. Já nos municípios com "PIB Alto", o coeficiente da variável serviços/PIB também é positivo e significativo; mas, o coeficiente da variável indústria/PIB é negativo e significativo, sinalizando que, na média, aumentos das participações dos demais setores geram maior crescimento do que a indústria. 
Em relação aos resultados dos controles que constam na Tabela 3, alguns destaques são interessantes. Os coeficientes negativos e significativos (Brasil e faixas de PIB) da variável PIB per capita sugerem que, quanto maior o PIB per capita municipal no início do período, menor o crescimento do PIB, ou seja, corroboram a hipótese de convergência de renda nos municípios. Como esperado, quanto maior o crescimento da população, menor o crescimento econômico. A proxy para capital humano (ensino médio) é associada a efeitos médios positivos, como é defendido pela literatura, mas o efeito só é significativo para os municípios de "PIB Alto".

Os resultados associados aos gastos públicos também condizem com a literatura que os defende como determinante do crescimento: efeitos positivos e significativos, excetuando-se os municípios de "PIB Baixo", para os quais não há significância estatística. Os coeficientes da variável investimentos/gastos - positivos e significativos, excetuando-se os municípios de "PIB Intermediário" - são outros em consonância com a literatura, sinalizando que a composição dos gastos públicos é relevante para gerar crescimento e que os investimentos são mais "produtivos" que outros tipos de despesas. Já os efeitos positivos e significativos - exceto nos municípios de "PIB Baixo" da variável arrecadação/receita apontam que quanto maior a dependência de recursos próprios para financiar gastos, mais elevado é o crescimento. A explicação pode estar relacionada à melhor "qualidade" dos gastos em função de um possível maior controle social.

Na Tabela 4, são apresentados os resultados das estimações que consideram o somatório das participações dos VAs da indústria e dos serviços no PIB e quanto a indústria representa no somatório dos VAs dos dois setores - respectivamente, as variáveis (indústria+serviços)/PIB e indústria/(indústria+serviços). Os resultados reforçam as evidências das estimações anteriores. No total dos municípios e nas amostras segmentadas pelo PIB per capita médio, a participação conjunta da indústria e dos serviços é associada a efeitos médios positivos e significativos sobre o crescimento, o que é sinalizado pelos coeficientes da variável (indústria+serviços)/PIB.

Tabela 4 - Efeitos da participação da indústria relativamente aos serviços sobre o crescimento

\begin{tabular}{|c|c|c|c|c|}
\hline Variáveis / Faixas de PIB & Brasil & PIB Baixo & PIB Intermediário & PIB Alto \\
\hline (Indústria+Serviços)/PIB & $\begin{array}{c}0,2802 * * * \\
(0,0067)\end{array}$ & $\begin{array}{c}0,0340 * * * \\
(0,0120)\end{array}$ & $\begin{array}{c}0,1511 * * * \\
(0,0080)\end{array}$ & $\begin{array}{c}0,1984 * * * \\
(0,0211)\end{array}$ \\
\hline Indústria/(Indústria+Serviços) & $\begin{array}{c}-0,2497 * * * \\
(0,0074)\end{array}$ & $\begin{array}{c}0,0441 * * \\
(0,0191)\end{array}$ & $\begin{array}{c}-0,1036^{* * *} * \\
(0,0087)\end{array}$ & $\begin{array}{c}-0,2440 * * * \\
(0,0186)\end{array}$ \\
\hline Controles & $\operatorname{Sim}$ & Sim & Sim & Sim \\
\hline Dummies Anuais & Sim & Sim & Sim & Sim \\
\hline Constantes & Sim & Sim & Sim & Sim \\
\hline Prob $>F$ & 0,0000 & 0,0000 & 0,0000 & 0,0000 \\
\hline Teste de Hausman & $2068,09 * * *$ & $781,13 * * *$ & $7635,78 * * *$ & $1190,22 * * *$ \\
\hline Observações & 47.163 & 8.880 & 28.572 & 9.711 \\
\hline
\end{tabular}

Erros-padrão robustos entre parênteses. *** Significativo a 1\%. ** Significativo a 5\%. * Significativo a $10 \%$.

Ainda na Tabela 4, os coeficientes associados à variável indústria/(indústria+serviços) sugerem que difere qual dos setores contribui mais para o crescimento econômico. Na amostra total, o coeficiente negativo e significativo associado à variável sinaliza que quanto maior a importância da indústria relativamente ao setor de serviços, menor o crescimento. O mesmo é observado nos municípios com "PIB Intermediário" e "PIB Alto". No entanto, nos municípios com "PIB Baixo", o coeficiente positivo e significativo associado à variável sugere que, quanto maior a participação da indústria relativamente ao setor de serviços, maior o crescimento.

Portanto, em linhas gerais, os resultados das Tabelas 3 e 4 para todos os municípios estão em consonância com os argumentos kaldorianos e os resultados empíricos que sugerem efeitos positivos da indústria sobre o crescimento. Além disso, também se alinham às evidências de trabalhos que sinalizam que, embora a indústria continue relevante, o setor de serviços passa a ter um papel mais expressivo para impulsionar o crescimento do PIB per capita das economias.

Os resultados por faixas de PIB per capita médio indicam que os efeitos médios positivos da participação industrial são relativamente maiores para os municípios de "PIB Baixo", o que sinaliza que o avanço da industrialização nos mesmos pode estar atrelado a impactos de ganhos de 
produtividade decorrentes da transferência de recursos da agropecuária para a indústria, com efeitos multiplicadores sobre o produto devido a economias de escala, ganhos de aprendizagem e transbordamentos produtivos e tecnológicos da atividade industrial sobre os demais setores. Porém, os efeitos médios da indústria sobre o crescimento diminuem nos municípios com "PIB Intermediário" e "PIB Alto", tornando-se menor que o efeito dos serviços e, no último grupo, que o dos demais setores da economia (agropecuária e público). Assim, a indústria perde força como o motor do crescimento em tais municípios, ao passo que os serviços ganham relevância.

Resgatando argumentos apresentados na primeira seção, é possível que tal fato decorra de ganhos de produtividade industrial que resultem em maior absorção de trabalhadores pelos serviços, com deslocamento de recursos para este setor e, assim, potencialização dos efeitos dessas atividades sobre o crescimento. Ademais, economias com rendas médias mais elevadas tendem a desenvolver serviços modernos, mais intensivos em conhecimento e tecnologia, com utilização de mão de obra mais qualificada, o que contribui para o aumento da produtividade do próprio setor e gera impactos positivos sobre competitividade e sofisticação tecnológica dos produtos industriais. Ainda cabe ressaltar que, em municípios de renda mais baixa, no geral, as atividades de serviços são mais tradicionais, intensivas em trabalho com menor grau de qualificação e com pouca incorporação de conteúdo tecnológico. Neste sentido, embora os efeitos potenciais dos serviços sobre o crescimento também sejam positivos, tendem a ser relativamente mais baixos.

Para investigar se o crescimento é afetado por maior especialização na produção industrial ou de serviços ou se, ao contrário, por maior diversificação entre os dois setores, é adaptado um indicador de Gini-Hirschmann para as participações destes setores. Quanto mais especializada (menos diversificada) for a economia, maior o indicador especialização indústria ou serviços.

A Tabela 5 apresenta os resultados das estimações que o consideram como variável explicativa de interesse. Considerando que a participação conjunta da indústria e dos serviços (indústria+serviços)/PIB - é associada a efeitos médios e significativos em todas as amostras, assim como nas estimações anteriores (Tabela 4), observa-se que, no total dos municípios e naqueles de "PIB Intermediário" e "PIB Alto", quanto maior a especialização em um dos dois setores considerados, maior o crescimento. Tal fato é sinalizado pelos coeficientes positivos e significativos associados à variável especialização indústria ou serviços. Assim, os possíveis ganhos de produtividade de setores individualizados parecem contribuir mais ao crescimento. Já nos municípios de "PIB Baixo", o resultado obtido sugere o inverso (coeficiente negativo).

Tabela 5 - Efeitos da especialização da produção em indústria ou serviços sobre o crescimento

\begin{tabular}{c|c|c|c|c}
\hline Variáveis / Faixas de PIB & Brasil & PIB Baixo & PIB Intermediário & PIB Alto \\
\hline \multirow{2}{*}{ (Indústria+Serviços)/PIB } & $0,2330^{* * *}$ & $0,0410^{* * *}$ & $0,1354 * *$ & $0,1003^{* * *}$ \\
& $(0,0065)$ & $(0,0117)$ & $(0,0076)$ & $(0,0199)$ \\
Especialização Indústria ou Serviços & $0,2467 * * *$ & $-0,0222^{*}$ & $0,1553^{* * *}$ & $0,0861^{* *}$ \\
& $(0,0132)$ & $(0,0107)$ & $(0,0138)$ & $(0,0396)$ \\
Controles & Sim & Sim & Sim & Sim \\
Dummies Anuais & Sim & Sim & Sim & Sim \\
Constantes & Sim & Sim & Sim & Sim \\
Prob > F & 0,0000 & 0,0000 & 0,0000 & 0,0000 \\
Teste de Hausman & $7943,44 * * *$ & $773,68 * * *$ & $7258,31^{* * *}$ & $1059,52^{* * *}$ \\
Observações & 47.163 & 8.880 & 28.572 & 9.711 \\
\hline
\end{tabular}

Erros-padrão robustos entre parênteses. *** Significativo a $1 \%$. ** Significativo a 5\%. * Significativo a $10 \%$.

Vale ressaltar que a participação dos serviços é relativamente superior à da indústria, tanto nos municípios de "PIB Baixo" como nos de "PIB Alto" (Tabela 2). Porém, a especialização em serviços nos municípios de renda mais alta parece surtir efeitos superiores em função dos atributos do setor, que tende a agregar mais valor em virtude da intensidade em conhecimento e conteúdo tecnológico, com impactos positivos potenciais sobre indústria e crescimento. Por outro lado, nos municípios de renda mais baixa, os serviços, geralmente, são caracterizados por serem de custos baixos, dada a intensidade de mão de obra pouco qualificada envolvida. Neste caso, a especialização 
em serviços não promoveria efeitos de transbordamento para os demais setores e, consequentemente, não implicaria em efeitos médios positivos sobre o crescimento ${ }^{5}$.

Na Tabela 6, são apresentados os resultados das estimações que avaliam, para a amostra total (Brasil), a existência de relações não lineares entre as participações dos VAs da indústria e dos serviços no PIB (indústria/PIB e serviços/PIB) e o crescimento econômico. Para garantir maior robustez aos resultados, são estimadas três especificações derivadas das equações (5) e (6). Na especificação I, são consideradas como variáveis explicativas a participação do VA do setor em discussão (em nível e ao quadrado) e as dummies anuais. Na especificação II, é controlada, ainda, a participação do outro setor. Já na especificação III, são adicionadas as covariadas.

Tabela 6 - Brasil: relações não lineares entre a participações da indústria e dos serviços e o crescimento

\begin{tabular}{|c|c|c|c|c|c|c|}
\hline \multirow{2}{*}{$\begin{array}{l}\text { Variáveis / Setores/ } \\
\text { Especificações }\end{array}$} & \multicolumn{3}{|c|}{ Relação não linear da Indústria/PIB } & \multicolumn{3}{|c|}{ Relação não linear dos Serviços/PIB } \\
\hline & I & II & III & $\mathbf{I}$ & II & III \\
\hline Indústria/PIB & $\begin{array}{c}0,2468 * * * \\
(0,0183)\end{array}$ & $\begin{array}{c}0,2576 * * * \\
(0,0177)\end{array}$ & $\begin{array}{c}0,0484 * * * \\
(0,0180)\end{array}$ & & $\begin{array}{l}0,0020^{*} \\
(0,0008)\end{array}$ & $\begin{array}{c}0,0417 * * * \\
(0,0088)\end{array}$ \\
\hline Indústria/PIB ${ }^{2}$ & $\begin{array}{c}-0,8698 * * * \\
(0,0274)\end{array}$ & $\begin{array}{c}-0,5756 * * * \\
(0,0269)\end{array}$ & $\begin{array}{c}-0,0615^{* *} \\
(0,0281)\end{array}$ & & & \\
\hline Serviços/PIB & & $\begin{array}{c}0,4200 * * * \\
(0,0072)\end{array}$ & $\begin{array}{c}0,3279 * * * \\
(0,0073)\end{array}$ & $\begin{array}{c}1,5480 * * * \\
(0,0270)\end{array}$ & $\begin{array}{c}1,5463 * * * \\
(0,0280)\end{array}$ & $\begin{array}{c}0,9027 * * * \\
(0,0301)\end{array}$ \\
\hline Serviços/PIB ${ }^{2}$ & & & & $\begin{array}{c}-1,0339 * * * \\
(0,0251)\end{array}$ & $\begin{array}{c}-1,0328 * * * \\
(0,0256)\end{array}$ & $\begin{array}{c}-0,5297 * * * \\
(0,0270)\end{array}$ \\
\hline Controles & Não & Não & Sim & Não & Não & Sim \\
\hline Dummies Anuais & Sim & Sim & Sim & Sim & Sim & Sim \\
\hline Constantes & Sim & Sim & Sim & Sim & Sim & Sim \\
\hline Prob $>$ F & 0,0000 & 0,0000 & 0,0000 & 0,0000 & 0,0000 & 0,0000 \\
\hline Teste de Hausman & $1684,11 * * *$ & $4546,60 * * *$ & $2153,83 * * *$ & $5258,85 * * *$ & $5248,44 * * *$ & $6247,92 * * *$ \\
\hline Observações & 49.946 & 49.946 & 47.098 & 49.946 & 49.946 & 47.098 \\
\hline$\overline{V A} / P I B$ máximo $(\%)$ & 14,19 & 22,38 & 39,35 & 74,86 & 74,86 & 85,21 \\
\hline
\end{tabular}

Erros-padrão robustos entre parênteses. *** Significativo a $1 \%$. ** Significativo a 5\%. * Significativo a $10 \%$.

Verifica-se, na Tabela 6, que os coeficientes estimados sugerem a existência, para os dois setores, de uma relação entre a participação de seus VAs no PIB e o crescimento econômico em formato próximo a um "U-invertido", uma vez que, além de serem significativos, respeitam o padrão de sinais para corroborar tal formato: positivo para a variável em nível e negativo para a variável ao quadrado. Assim, para níveis baixos de participação de um dos setores, a expansão desta resulta em maior crescimento; porém, atingida certa participação (turning point), sua expansão gera menor crescimento. Na última linha da tabela constam os turning points médios $(\overline{V A} / P I B)$ - pontos de máximo. Observa-se que, em todas as especificações, os serviços devem atingir participação bem superior à indústria para que sua expansão deixe de gerar maior crescimento econômico. Assim, é plausível inferir que a especialização da produção municipal benéfica ao crescimento, constatada nas estimações anteriores (Tabela 5), é a concentrada nos serviços.

Vale ressalvar que os menores turning points na especificação $I$, em especial na indústria, decorre do fato de não ser controlada nesta a participação do outro setor relevante para o estudo. Assim, a participação do setor em discussão é relativa a todos os outros setores. Por outro lado, nas demais especificações, são consideradas as participações dos dois setores de maior interesse (indústria e serviços), de modo que o resultado é relação aos demais (agropecuária e público).

As Tabelas 7 e 8 mostram os resultados que avaliam a existência das relações não lineares para as amostras de municípios segmentadas por faixas de PIB per capita médio. Nesse caso, são reportados somente os resultados obtidos pela especificação III (com todos os controles). Verifica-se que, nos três conjuntos de municípios e nos dois setores, os coeficientes estimados sugerem a existência da relação entre a participação do VA do setor e o crescimento econômico em um formato

\footnotetext{
${ }^{5}$ Para uma análise sobre as características do setor de serviços brasileiro, de acordo com o tipo de serviços, e seus impactos sobre a competitividade industrial por setores, conferir CNI (2014).
} 
próximo a um "U-invertido", pois, além de significativos, respeitam o padrão de sinais para corroborar o formato: positivo para a variável em nível e negativo ao quadrado.

No caso do setor industrial, a Tabela 7 mostra que, nos municípios com "PIB Baixo" e "PIB Alto", os turning points são próximos, entre $51 \%$ e $53 \%$; enquanto que nos municípios de "PIB Intermediário", o turning point é bastante inferior (em torno de 18\%), o que pode motivar investigações futuras sobre as causas de tal fenômeno, mas que fogem do escopo deste estudo.

Tabela 7 - Faixas de PIB: relações não lineares entre a participação da indústria e o crescimento

\begin{tabular}{c|c|c|c}
\hline Variáveis / Faixas de PIB & PIB Baixo & PIB Intermediário & PIB Alto \\
\hline Indústria/PIB & $0,3210^{* * *}$ & $0,2151^{* * *}$ & $0,3799^{* * *}$ \\
& $(0,0510)$ & $(0,0220)$ & $(0,0514)$ \\
Indústria/PIB ${ }^{2}$ & $-0,7994^{* * *}$ & $-0,4284^{* * *}$ & $-0,6965^{* * *}$ \\
& $(0,1193)$ & $(0,0399)$ & $(0,0649)$ \\
Serviços/PIB & $0,2941^{* * *}$ & $0,4455^{* * *}$ & $0,4424 * * *$ \\
Controles & $(0,0119)$ & $(0,0083)$ & $(0,0247)$ \\
Dummies Anuais & Sim & Sim & Sim \\
Constantes & Sim & Sim & Sim \\
Prob $>\mathrm{F}$ & Sim & Sim & 0,0000 \\
Teste de Hausman & $438,78^{* * *}$ & 0,0000 & $615,39 * *$ \\
Observações & 8.880 & $3143,66 * * *$ & 9.711 \\
\hline$V A$
\end{tabular}

Erros-padrão robustos entre parênteses. *** Significativo a 1\%.** Significativo a 5\%. * Significativo a $10 \%$.

Comparando com os resultados da Tabela 3, deve-se ressalvar que, dada a não linearidade observada na Tabela 7, os efeitos positivos da indústria nos municípios com "PIB Baixo" e "PIB Intermediário" sugerem que prevalecem os efeitos médios nos municípios no segmento ascendente da relação entre participação industrial e crescimento; já o coeficiente negativo nos municípios com "PIB Alto" sinalizam que prevalecem os efeitos nos municípios no segmento descendente. Ademais, a participação industrial média é maior no último grupo (Tabelas 1 e 2).

Tabela 8 - Faixas de PIB: relações não lineares entre a participação dos serviços e o crescimento

\begin{tabular}{|c|c|c|c|}
\hline Variáveis / Faixas de PIB & PIB Baixo & PIB Intermediário & PIB Alto \\
\hline \multirow{2}{*}{ Indústria/PIB } & $0,0331 *$ & $0,0258 * *$ & $-0,0204^{*}$ \\
\hline & $(0,0115)$ & $(0,0105)$ & $(0,0101)$ \\
\hline \multirow{2}{*}{ Serviços/PIB } & $1,1947 * * *$ & $1,4887 * * *$ & $2,0693 * * *$ \\
\hline & $(0,0837)$ & $(0,0358)$ & $(0,0813)$ \\
\hline \multirow{2}{*}{ Serviços/PIB ${ }^{2}$} & $-0,6960 * * *$ & $-0,9659 * * *$ & $-1,7539 * * *$ \\
\hline & $(0,0659)$ & $(0,0329)$ & $(0,0863)$ \\
\hline Controles & Sim & Sim & Sim \\
\hline Dummies Anuais & Sim & Sim & Sim \\
\hline Constantes & Sim & Sim & Sim \\
\hline Prob $>F$ & 0,0000 & 0,0000 & 0,0000 \\
\hline Teste de Hausman & $497,61 * * *$ & $3273,96 * * *$ & $754,36 * * *$ \\
\hline Observações & 8.880 & 28.572 & 9.711 \\
\hline$\overline{V A} / P I B$ máximo $(\%)$ & 85,83 & 77,06 & 58,99 \\
\hline
\end{tabular}

Erros-padrão robustos entre parênteses. *** Significativo a $1 \%$. ** Significativo a 5\%. * Significativo a $10 \%$.

No caso dos serviços, a Tabela 8 mostra que, nos municípios com "PIB Baixo", o turning point é de aproximadamente 86\%; nos municípios com "PIB Intermediário", é de 77\%; já nos municípios com "PIB Alto", é bastante inferior aos demais, próximo a 59\%. Constatada a não linearidade, comparando com os resultados da Tabela 3, pode-se inferir que, na média, o efeito positivo dos municípios que estão na fase ascendente da relação entre a participação do VA dos serviços no PIB e o crescimento econômico prevalece, até porque, em todas as faixas de PIB per capita, a participação média dos serviços é bastante inferior ao respectivo turning point (Tabelas $1 \mathrm{e}$ 2). Já comparando com os turning points da Tabela 7, verifica-se que, em todas as faixas de PIB per 
capita, assim como no total (Tabela 6), os serviços devem atingir participação bem superior à indústria para que sua expansão não resulte em maior crescimento econômico.

Os resultados das estimações que constam nas Tabelas 6 a 8 se alinham aos argumentos da literatura que enfatiza o ganho de relevância dos serviços sobre o crescimento econômico. As evidências sugerem que maior grau de industrialização tem um limite em termos de efeitos positivos sobre a expansão do PIB per capita. Contudo, vale ressalvar que, nos municípios com renda baixa, o avanço da participação industrial pode resultar nos efeitos kaldorianos esperados sobre o crescimento, ao passo que o setor de serviços intensivo em trabalho pouco qualificado não consegue potencializar seus efeitos sobre o produto. Nos municípios de renda mais elevada, a maior participação da indústria e a consequente sofisticação tecnológica dos seus produtos exigem serviços modernos, caracterizados pela utilização de capital humano especializado, de modo que suas elevações de produtividade transbordam para a indústria e potencializam seus efeitos sobre o crescimento, como é defendido em vários trabalhos, como CNI (2014) e Giovanini et al. (2016).

\section{Considerações finais}

As atividades industriais são consideradas pela literatura de inspiração kaldoriana como fundamentais para o crescimento da renda/produto das economias no longo prazo (engine of growth hypothesis). Porém, evidências empíricas recentes, apesar de não refutarem a hipótese da indústria como motor do crescimento, apontam que os serviços passam a ter papel relevante, principalmente em economias desenvolvidas. Contribuindo para este debate, o presente estudo averigua a importância das participações da indústria e dos serviços no PIB para o crescimento econômico dos municípios brasileiros. São realizadas estimações em painel com dados de 1999 a 2012 para o conjunto dos municípios e para os municípios segmentados por faixas de PIB per capita médio.

Resumidamente, as evidências obtidas sinalizam que, para a amostra total, a indústria é relevante para explicar o crescimento. Porém, os serviços apresentam efeitos médios superiores, o que sugere uma maior importância deste setor como motor do crescimento para os municípios brasileiros no período considerado. Para as análises por faixas de PIB per capita médio, deve-se destacar que, nos municípios de renda mais baixa, o papel da indústria para o crescimento é mais importante do que o dos serviços. Já nos municípios com níveis de renda mais elevados, os serviços possuem efeitos médios superiores sobre o crescimento econômico, o que está em consonância com evidências internacionais de países com níveis distintos de desenvolvimento.

As evidências sugerem, ainda, que, nos municípios com níveis mais baixos de renda, a especialização da produção municipal nos serviços ou na indústria não resulta em impactos positivos sobre o crescimento econômico, ao passo que, nos municípios de renda mais elevada, a especialização em um dos setores é relevante para o crescimento. Por fim, são encontradas relações não lineares, em um formato próximo a um "U-invertido", entre o crescimento e as participações dos VAs da indústria e dos serviços no PIB, sugerindo que contribuições positivas dos dois setores têm efeitos limitados sobre o crescimento (turning points). Ou seja, à medida que a participação de um dos setores aumenta, o crescimento econômico é maior; contudo, este passa a diminuir a partir de determinada participação. Os turning points médios dos serviços são bastante superiores aos da indústria, o que sinaliza que os serviços devem atingir maiores participações para que sua expansão deixe gerar maior crescimento econômico. Portanto, são observados efeitos heterogêneos da indústria e dos serviços sobre o crescimento econômico em função do nível de PIB municipal per capita médio e das próprias participações setoriais.

Levando em conta os resultados observados no presente estudo e argumentos da literatura econômica, vale ressaltar que políticas voltadas ao setor industrial são relevantes para estimular o crescimento econômico, sobretudo, em economias (municípios) com níveis mais baixos de renda. Porém, o setor de serviços deve ser pensado também como um setor estratégico, cuja modernização e sofisticação contribui para aumentar a competitividade de outros setores. Tal recomendação é válida, sobretudo, no caso dos serviços dotados de maior valor agregado pela utilização de tecnologia 
elaborada e de mão de obra qualificada, visto a maior capacidade de gerar efeitos expressivos sobre o processo de crescimento, quando comparados aos serviços menos sofisticados.

Cabe ressaltar que, nos munícipios, especialmente pequenos e médios, os serviços tendem a ser concentrar em comércio e administração pública, além de predominar sobre as atividades industriais. Ademais, as indústrias naqueles municípios, quando existentes, são, sobretudo, baseadas em atividades com menor conteúdo tecnológico. Neste sentido, como possibilidade de trabalhos futuros, há que se avaliar as hipóteses deste trabalho estimando modelos para alguns setores de serviços específicos em relação à indústria. Outra possibilidade seria avaliar conforme grandes regiões do país, desagregando a análise para as capitais e/ou regiões metropolitanas.

\section{Referências bibliográficas}

ASCHAUER, D. A. Is public expenditure productive? Journal of Monetary Economics, v. 23, n. 2, p. 177-200, 1989.

BALTAGI, B. H. Econometric analysis of panel data. Wiley and Sons Ltda., 2001.

BARRO, R. J. Government spending in a simple model of endogenous growth. Journal of political Economy, v. 98, p. 103-125, 1990.

BARRO, R.; SALA-I-MARTIN, X. Convergence. Journal of Political Economy, n. 2, 1992.

BARRO, R.; SALA-I-MARTIN, X. Technological diffusion, convergence and growth. Journal of Economic Growth, v. 1, p. 1-26, 1997.

BAUMOL, W. J. Macro-economics of unbalanced growth: the anatomy of urban crises. American Economic Review, n.57(3), 415-26, 1967.

BAUMOL, W. J. Productivity growth, convergence and welfare: what the long-run data show. American Economic Review. v. 76, p. 1072-1085, 1986.

BAUMOL, W.J.; WOLFF, E.N. Productivity growth, convergence, and welfare: reply. American Economic Review, v. 78(5), p. 1155-59, 1988.

CARDOSO, V. L.; PEROBELLI, F. S. A intensidade de serviços na economia brasileira: uma abordagem de insumo-produto. Anais do $41^{\circ}$ Encontro Nacional de Economia, ANPEC, Foz do Iguaçu, Dez., 2013.

CNI. Serviços e competitividade industrial no Brasil. Confederação Nacional da Indústria, Brasília, 2014.

DASGUPTA, S.; SINGH, A. Manufacturing, services and premature deindustrialization in developing countries: a Kaldorian analysis. UNU-WIDER Research Paper, n.49. May, 2006.

DEVARAJAN, S.; SWAROOP, V.; ZOU, H. The composition of public expenditure and economic growth. Journal of Monetary Economics, v. 37, n. 2, p. 313-344, 1996.

EASTERLY, W.; REBELO, S. Fiscal policy and economic growth. Journal of Monetary Economics, v. 32, n. 3, p. 417-458, 1993.

GIOVANINI, A.; AREND, M.; PEREIRA, V. Contribuição dos serviços para o crescimento econômico: a quinta lei de Kaldor. Prêmio da Associação Brasileira de Desenvolvimento, Coletânea de artigos premiados pela ABDE-BID. 1ed. ABDE Editorial, Rio de Janeiro, 2016.

GOMES, G. M. MACDOWELL, M. C. Descentralização política, federalismo fiscal e criação de municípios: o que é mau para o econômico, nem sempre é bom para o social. Texto para Discussão do IPEA, n. 706, 2000.

JACINTO, P. A.; RIBEIRO, E. P. Crescimento da produtividade no setor de serviços e da indústria no Brasil: dinâmica e heterogeneidade. Economia Aplicada, v. 19, n. 3, 2015.

KALDOR, N. Causes of the slow rate of economic growth of the United Kingdom: an inaugural lecture. Cambridge University Press, 1966. 
LAMONICA, M. T.; FEIJÓ, C. A. Crescimento e industrialização no Brasil: uma interpretação à luz das propostas de Kaldor. Revista de Economia Política, v. 31, n. 1(121), jan./mar. 2011.

MANKIW, N. G.; ROMER, D.; WEIL, D. N. A contribution to the empirics of economic growth. The Quarterly Journal of Economics, v. 107, n. 2, p. 407-437, 1992.

MARQUES JUNIOR, L. S. Equivalência ricardiana e os efeitos da política físcal na economia brasileira. Análise Econômica, Porto Alegre, v. 33, p. 215-241, n. 64, set., 2015.

MARQUETTI, A. A.; BÊNI, D. A.; MARQUES, A. M. Determinantes dos diferenciais das taxas de crescimento sub-regionais do Rio Grande do Sul nos anos 90. Ensaios FEE, Porto Alegre, v. 26, Número Especial, p. 95-116, maio, 2005.

MENDES, M. J. Capture of fiscal transfers: a study of Brazilian local governments. Revista de Economia Aplicada, v. 9, p. 427-444, 2005.

NAUDÉ, W.; SZIRMAI, A. The importance of manufacturing in economic development: Past, present and future perspectives. UNU-MERIT Working Paper Series, n.41, 2012.

OLIVEIRA, C. W. A.; RODRIGUES JÚNIOR, W. Crescimento econômico, convergência de renda e elementos espaciais. In: CRUZ, B. O.; FURTADO, B. A.; MONASTERIO, L.; RODRIGUES JÚNIOR (orgs.) Economia Regional e Urbana: teorias e métodos com ênfase no Brasil. Instituto de Pesquisa Econômica Aplicada (IPEA), 2011.

OREIRO, J. L.; FEIJÓ, C. A. Desindustrialização: conceituação, causas, efeitos e o caso brasileiro. Revista de Economia Política, v. 30, n. 2, abr./jun. 2010.

PARK, D.; SHIN, K. The service sector in Asia: is it an engine of growth? ADB Economics Working Paper Series, n. 322, Dec., 2012.

ROCHA, F.; GIUBERTI, A. C. Composição do gasto público e crescimento econômico: uma avaliação macroeconômica da qualidade dos gastos dos Estados brasileiros. Economia Aplicada, v. 11, n. 4, out.-dez., 2007.

RODRIK, D. Growth after the crisis. Commission on Growth and Development Working Paper, n.65. World Bank, Washington, DC, 2009.

SILVA, C. M.; MENEZES FILHO, N.; KOMATSU, B. Uma abordagem sobre o setor de serviços na economia brasileira, INSPER Policy Paper, n. 19, Ago., 2016.

SOLOW, R. M. A contribution to the Theory of Economic Growth. Quarterly Journal of Economics, v. LXX, p. 65-94, 1956.

SZIRMAI, A.; VERSPAGEN, B. Manufacturing and economic growth in developing countries 19502005. UNU-MERIT Working Paper Series, n.69, Dec., 2011.

TIMMER M. P.; G. J. DE VRIES. Structural change and growth accelerations in Asia and Latin America: a new sectoral dataset. Cliometrica, v.3(2), p. 165-190, June, 2009.

TREGENNA, F. Deindustrialisation, structural change and sustainable economic growth. UNIDO Working Paper, n.2 Vienna, 2015.

THIRLWALL, A. P. A Natureza do crescimento econômico: um referencial alternativo para compreender o desempenho das nações. IPEA, Brasília, 2005.

VIEIRA, F. V.; AVELLAR, A. P. M.; VERÍSSIMO, M. P. Indústria e crescimento econômico: evidências para países desenvolvidos e em desenvolvimento. Revista de Economia Política, v.34, n.3, p.485-502, jul.-set., 2014.

VIEIRA, F. V.; VERÍSSIMO, M. P.; AVELLAR, A. P. M. Indústria e crescimento: uma análise de painel para os estados brasileiros. Análise Econômica, Porto Alegre, n. 65, mar., 2016.

WOOLDRIDGE, J. M. Introductory econometrics. Pioneira Thomson Learning, 20 ed., 2002. 